\title{
O BALANCING TEST COMO TÉCNICA DE PONDERAÇÃO NAS QUESTÕES DE LIMITAÇÃO DA LIBERDADE DE EXPRESSÃO DO PENSAMENTO DO TRABALHADOR
}

\author{
Anna Leticia Piccoli ${ }^{1}$ \\ Rosane Machado Carneiro ${ }^{2}$
}

\section{RESUMO}

O tema deste artigo é a liberdade de expressão do pensamento, com recorte na limitação deste direito na esfera trabalhista e a validade dessa limitação a partir da técnica do balancing test. O problema consiste em estabelecer parâmetros a partir da análise de casos concretos pela técnica do balancing test, verificando a validade ou não da limitação, decorrente da relação de trabalho, do direito à liberdade de expressão do pensamento. A pesquisa será estruturada em três capítulos por meio de aprofundamento investigativo, através de pesquisa descritivoexplicativa do tipo documental-bibliográfica, em doutrinas e apelo em jurisprudências, com viés indutivo.

Palavras-chave: Liberdade de expressão; Relação de trabalho; Ponderação; Balancing test.

\section{THE BALANCING TEST AS A TECHNIQUE OF WEIGHTING IN THE QUESTIONS OF LIMITING THE FREEDOM OF EXPRESSION OF WORKER'S THOUGHT}

\begin{abstract}
The theme of this article is the freedom of expression of thought, with cutout on this limitation law in labour sphere and the validity of that limitation from the analysis based on the criteria of the balancing test. The problem is whether, by analyzing specific cases by means of the criteria established by the technique of balancing test to limit the right to freedom of expression of thought deriving from employment relationship has or not valid. The research will be structured in three chapters through investigative, deepening through research-descriptive explanatory documentary-type in bibliographical doctrines and appeal judgments with inductive bias.
\end{abstract}

Keywords: Freedom of expression; Labour relationship; Working relationship; Weighting; Balancing test.

\section{INTRODUÇÃO}

\footnotetext{
${ }^{1}$ Advogada. Mestranda em Direitos fundamentais sociais: relações de trabalho e seguridade social pelo Programa de pós-graduação stricto sensu da Universidade do Oeste de Santa Catarina - Unoesc (2017). Especialista em Novo Sistema Processual Civil Brasileiro pelo Centro de Excelência em Direito (Chapecó). Graduada em Direito pela Universidade do Oeste de Santa Catarina (Unoesc - Xanxerê). Endereço eletrônico annaleticiapiccoli@gmail.com

${ }^{2}$ Advogada. Mestranda em Direitos fundamentais sociais: relações de trabalho e seguridade social pelo Programa de pós-graduação stricto sensu da Universidade do Oeste de Santa Catarina - Unoesc (2017). Especialista em Ciências Jurídicas. (UNOESC - SMO). Pós Graduação em Novo Sistema Processual Civil Brasileiro- Centro de Excelência em Direito (Chapecó). Especialização em Didática da Educação Superior. Especialização em Pós Graduação em Direito e Processo do Trabalho. (IMED Passo Fundo) Especialização em ESMESC Escola de Magistratura (UNOESC -SMO) Graduada em Direito pela Universidade do Oeste de Santa Catarina (UnoescChapecó). Endereço eletrônico advrosanemachado@gmail.com
} 
Este artigo busca fazer uma análise sob os critérios do "balancing test" em casos concretos que julgaram a validação da limitação da liberdade de expressão do pensamento decorrentes da relação de trabalho entre as partes. Para tanto, busca-se examinar obras que tragam um conceito amplo do direito ora estudado, além da análise das disposições jurídicas brasileiras, um breve estudo sobre as mudanças que as novas mídias sociais e tecnologias de informação trouxeram; bem como as possibilidades de limitação deste direito fundamental.

Por fim, compreendem-se os critérios de análise do "balancing test" para saber se os tribunais do trabalho têm a utilizado para tomar as decisões acerca de aparentes conflitos entre o poder diretivo e o direito de liberdade e expressão do pensamento do trabalhador.

O tema do estudo é a limitação da liberdade de manifestação do pensamento do trabalhador pelo empregador nas relações de trabalho, delimitado pela sua manifestação em redes sociais pelo empregador, no ambiente virtual de trabalho ou fora dele, e sua limitação como expressão do poder diretivo decorrente da relação de trabalho, diante do direito à liberdade de manifestação do pensamento do trabalhador e o "balancing test" como técnica judicial de ponderação e conclusão acerca dos limites da validade dessa limitação.

O problema consiste em saber como verificar, a partir da técnica judicial do "balancing test", os limites razoáveis para a admissão da validade jurídica de uma limitação imposta, em um caso concreto, pelo empregador à liberdade de manifestação do pensamento do trabalhador em redes sociais no ambiente virtual de trabalho ou fora dele, justificado pelo elevado número de aparentes conflitos entre o direito à liberdade de expressão do pensamento e demais direitos.

O objetivo geral é compreender, identificando-os, diante do caráter fundamental do direito à liberdade de manifestação do pensamento do trabalhador e do poder diretivo do empregador, decorrente da relação de trabalho, quais são os itens de análise, segundo a técnica judicial do "balancing test", que permitem aferir os limites juridicamente válidos de uma limitação imposta, em um caso concreto, pelo empregador à liberdade de manifestação do pensamento do trabalhador em redes sociais no ambiente virtual de trabalho ou fora dele.

Para tanto, os objetivos específicos são compreender o alcance e atualidade do direito à liberdade de manifestação do pensamento como direito fundamental, e do seu desdobramento sobre a manifestação do pensamento do trabalhador em redes sociais no ambiente virtual de trabalho ou fora dele; compreender, delineando-o, o poder diretivo do empregador, decorrente da relação de trabalho; e compreender, identificando-os, os itens que 
de análise que integram a técnica judicial do "balancing test", analisando dois casos concretos em que foi discutida tal limitação e verificando se a técnica judicial de ponderação estudada foi utilizada no caso julgado.

A pesquisa será estruturada em três capítulos por meio de aprofundamento investigativo, através de pesquisa descritivo-explicativa do tipo documental-bibliográfica, em doutrinas e apelo em jurisprudências, com viés indutivo.

A primeira parte da pesquisa dedica-se a compreender as liberdades em sentido amplo, realizando uma pesquisa em filósofos, doutrinadores e no ordenamento jurídico brasileiro, cuja disposição encontra-se precipuamente da Constituição Federal, a possibilidade de sua limitação e seu comportamento diante das novas tecnologias e redes sociais.

A pesquisa debruça-se de forma mais acentuada na liberdade de expressão e pensamento e as possibilidades de sua limitação, compreendendo que a liberdade de pensamento é de foro íntimo, porquanto incapaz de ofender outrem. Portanto, as celeumas que chegam ao poder judiciário para análise sempre se referem à manifestação do pensamento que, inobstante tenha induvidoso caráter fundamental, não é absoluto.

O segundo capítulo dedica-se em compreender a relação de trabalho, as prerrogativas do empregador decorrente do poder diretivo e a possibilidade de limitação da liberdade de expressão do pensamento do trabalhador em redes sociais, dentro e fora das relações de trabalho. Aborda, ainda, a subordinação do trabalhador e quais são os limites da prestação do serviço como aluguel do próprio corpo - força física ou intelectual - possibilitando ao empregador tomar decisões que, por vezes, impactam na intimidade do trabalhador.

O último capítulo possui um viés voltado aos conflitos inerentes ao exercício direito à liberdade de expressão do pensamento e, se sua limitação incorreu em violação deste direito ou manutenção da ordem e demais direitos de outros cidadãos. Para tanto, extraíram-se alguns critérios de análise a partir da técnica judicial de ponderação do "balancing test", analisando duas decisões tomadas por tribunais do trabalho, aplicando os critérios aferidos e percebendo se a técnica foi ou não aplicada e quais as consequências disso.

Garantir a liberdade é, acima de tudo, uma forma de garantir a própria democracia e a dignidade da pessoa humana, vez que respeita diversos valores e propicia que os cidadãos, além de estarem protegidos das arbitrariedades do Estado, participem das decisões dos poderes, garantindo a ordem social e todos os direitos que necessitam da liberdade para serem exercidos. 
Por fim, é possível perceber que tanto não há uma definição específica acerca das possibilidades da limitação do direito a liberdade de expressão do pensamento quanto não há uma definição de como as decisões judiciais devem ser tomadas, ampliando, por vezes, a discricionariedades dos magistrados, sem qualquer concretude nas ponderações realizadas.

\section{A LIBERDADE DE MANIFESTAÇÃO DO PENSAMENTO COMO DIREITO FUNDAMENTAL E AS REDES SOCIAIS}

Desde as eras mais remotas vez que cada homem poderia fazer o que fosse preciso para proteger sua própria vida. Sob este fundamento, os súditos renunciaram seus direitos no pacto de submissão, criando um Estado absoluto e centralizador (O Leviatã) que tem o dever de garantir a segurança e a vida (HOBBES, 2009, p. 98). Motivo pelo qual a liberdade é reconhecida como direito desde antes mesmo do surgimento da sociedade e decorrente dela que o ser humano passa a relacionar-se com os seus semelhantes, tornando sua sobrevivência mais fácil a partir da divisão de tarefas.

John Stuart Mill (1086, p.17) vislumbra a luta entre a liberdade e a autoridade como característica predominante das épocas da história. A liberdade era entendida como limitação dos poderes dos governantes absolutistas e como proteção contra sua tirania. Compreende-se, portanto, que a mesma liberdade que entrega parte de seus direitos para que o Estado lhes dê proteção é a liberdade que proíbe que os membros do Estado lhes retirem direitos garantidos.

Hobbes (2009, p. 97), por sua vez, apresenta um conceito de liberdade em que é permitido realizar tudo o que não for prescrito em lei. Mill $(1086$, p. 26) acredita que quando o povo sentir o poder do governo com o seu poder e as opiniões do governo como suas opiniões "a liberdade individual provavelmente estará tão exposta à invasão do governo, quanto já esta da opinião pública”. De outro quadrante, Montesquieu (1998, p. 139) acredita que liberdade é fazer aquilo que a Constituição autoriza: “A liberdade é o direito de fazer tudo quanto às leis permitem; e, se um cidadão pudesse fazer o que elas proíbem, não mais teria liberdade, porque os outros teriam idêntico poder".

Kant (1980a, p. 232) ainda entende a liberdade como ponto de vista prático no momento em que se é capaz de agir sem ser necessariamente instigado por uma emoção. Pode ser vista, também, como positiva ou negativa: a primeira consiste em uma única ação, enquanto a segunda é uma alternativa, em sentido mais amplo. Para garantir tão nobre direito não se faz necessário um direito de prestação, mas um direito de defesa do Estado. 
Este direito é a busca pela realização do ser humano, tornando-o responsável pelas suas escolhas. Devido os possíveis conflitos resultantes das pretensões que aparentemente colidem estas liberdades o Estado se justifica, incumbido de garantir a paz de seus cidadãos. Imprescindível salientar que a liberdade tem um cunho histórico e depende do poder do homem sobre a natureza, a sociedade e sobre si mesmo em determinado momento, ampliando as liberdades em uma grandeza diretamente proporcional à evolução da humanidade, transformando-se na medida em que a atividade humana se alarga. A liberdade é, ainda, inerente à natureza humana, sendo dever do Estado seu reconhecimento, regulação e restrição.

Os direitos de liberdade estão dispostos na Declaração Universal dos direitos Humanos tanto quanto na Constituição da República Federativa do Brasil como elementos da dignidade da pessoa humana, considerada a espinha dorsal do sistema fundamental do Estado Democrático de Direito. A liberdade, por ser uma das protagonistas dos direitos fundamentais, passou pela mesma evolução histórica que estes. Em 1948, a Declaração Universal dos Direitos Humanos (cuja base serviu para configuração da positivação dos direitos fundamentais brasileiros) afirmou em seu artigo primeiro que todos os indivíduos nascem em pleno gozo de sua liberdade e igualdade, em direitos e dignidade. No artigo terceiro, reitera que todo homem tem direito a vida, a liberdade e a segurança.

No Brasil, a gênese da positivação da liberdade se deu logo após a independência, quando a primeira Carta Constitucional abarcou os direitos fundamentais em um título exclusivo, tendo por fundamento o direito à liberdade. As Constituições seguintes seguiram o mesmo critério. As liberdades asseguradas pelo ordenamento jurídico brasileiro de hoje, dispostos nos múltiplos incisos do artigo quinto da Constituição Federal $^{3}$, podem ser discriminadas em várias espécies, cada qual com suas características e objetivos próprios. Entretanto, essa pesquisa terá uma dedicação especial à liberdade de expressão e de pensamento e suas limitações.

A liberdade de expressão de pensamento é uma das mais importantes espécies de liberdade dos direitos fundamentais, sonhada e reivindicada pelos homens de todas as eras. Ademais, é de senso comum que o ser humano não consegue viver sozinho e, portanto, é indispensável à comunicação, cuja acessibilidade é permitida pela expressão de pensamentos, permitindo os homens descubram seus objetivos e ideais comuns.

\footnotetext{
${ }^{3}$ Art. $5^{\circ}$ da Constituição Federal da República Federativa do Brasil: "Todos são iguais perante a lei, sem distinção de qualquer natureza, garantindo-se aos brasileiros e aos estrangeiros residentes no País a inviolabilidade do direito à vida, à liberdade, à igualdade, à segurança e à propriedade, nos termos seguintes.
}

Rev. do Dir. do Trabalho e Meio Ambiente do Trabalho | e-ISSN: 2525-9857 | Salvador | v. 4 | n. 1 | p. 19 - 
Entretanto, a liberdade de pensamento é de foro íntimo, e enquanto não manifestada é livre sempre, porquanto incapaz de ofender outrem, sendo que é impossível constranger alguém a pensar desta ou daquela forma. Assim, sendo o pensamento intrínseco e, portanto, não pode ser vedado, tem-se a discussão a respeito de sua exteriorização. É evidente que como todos os direitos, este não é ilimitado, restringindo-se às ações que não tragam prejuízo ou embaraços a outrem.

O ser humano possui em sua natureza o instinto de persuasão. Não basta entender as informações e criar opiniões sobre ela, tampouco manifestá-las: é de sua natureza buscar convencer todos ao seu redor de que sua ideia é a mais correta, e que a informação deve ser vista desta forma por todos. O pensamento, nada mais é do que um juízo de valor, uma reflexão e apenas sua expressão que pode atingir outras pessoas.

Neste diapasão, a Constituição Federal brasileira garante a liberdade de pensamento e de expressão, vedado o anonimato ${ }^{4}$. Na hipótese da manifestação do pensamento causar dano à moral ou à imagem de outrem, deverá ser ressarcido em indenização, além do direito de resposta, de mesmo patamar. Isto porque o texto constitucional não torna legal apenas a manifestação de simples informação, mas a opinião sobre elas seja favorável ou contra, e de qualquer forma - escrita ou oral.

Este direito está ligado umbilicalmente com o direito à informação, colidindo aparentemente com a honra, imagem e a privacidade por várias vezes. Por tal motivo não é estendido uniformemente, mas sujeito a limitações. Frequentemente o protagonista do polo passivo desta relação é o Poder Público, que detém a capacidade de coação daqueles que agem em desacordo com seus princípios.

Desta forma, o Estado não pode proibir a veiculação na imprensa de alguma informação, mas nada impede que o editor ou dono do meio de comunicação não autorize publicar determinado artigo, vez que nas relações individuais deve-se fazer um balanço dos interesses envolvidos. Por este motivo, a liberdade de expressão surge com o intuito de evitar que o Estado passe a exercer a censura que constitui uma ação governamental, de ordem prévia, centrada sobre o conteúdo de uma mensagem. Portanto, proibir a censura significa que as ideias, antes de serem divulgadas, não precisam passar por qualquer agente estatal.

A liberdade de pensar é, portanto, impossível de ser restrita, cabendo à pessoa controlar aquilo que quer compartilhar com a sociedade. Quando o sujeito de direito não é capaz de realizar referida ponderação, o judiciário se torna responsável por decidir acerca dos

\footnotetext{
${ }^{4}$ Artigo $5^{\circ}$, IX da Constituição Federal da República Federativa do Brasil: "é livre a expressão da atividade intelectual, artística, científica e de comunicação, independentemente de censura ou licença".
}

Rev. do Dir. do Trabalho e Meio Ambiente do Trabalho | e-ISSN: 2525-9857 | Salvador | v. 4 | n. 1 | p. 19 - 
direitos violados pela ideia expressa - se possuem força normativa para limitá-la. O destaque que se dá a este direito é relativo à importância que ele tem na construção da personalidade dos indivíduos, além da eterna busca pela verdade real, e da indispensabilidade do que concerne à manutenção da democracia: a crítica aos governantes é essencial quando se trata do controle da atividade política.

No mesmo sentido, Moraes (2002, p. 118) defende a manifestação dos pensamentos não apenas por ser favorável ao sistema político-jurídico, mas principalmente pela a análise crítica, cuja expressão enaltece os propósitos do Estado Democrático de Direito, partindo-se do pressuposto que a democracia só existe a partir do pluralismo de ideias, da tolerância de opiniões e da facilidade do diálogo. O inciso IV do artigo quinto da Constituição Federal do Brasil $^{5}$ encontra reforço no artigo $220^{6}$ da mesma legislação, acolhendo a interlocução entre pessoas presentes, por meio de diálogos e discussões. Ademais, tendo em vista que ninguém é obrigado a produzir prova contra si mesmo e que ninguém pode ser coagido a expressar seus posicionamentos, o direito de permanecer calado faz parte da liberdade de pensamento.

O surgimento de novas tecnologias de informações deu ensejo ao aparecimento de novos direitos, relacionados, acima de tudo, com um novo paradigma de sociedade, cujo pilar tornou-se a informação. Isto porque as novas tecnologias facilitaram a troca de informação e muito mais veloz sua propagação, devendo ser utilizados os direitos de forma a suprir as novas necessidades da sociedade.

O desenvolvimento dos meios tecnológicos, aliado a seu aprimoramento propiciou uma modificação nos eixos sociais, vez que os avanços do século XX provocaram uma nova forma de pensar e agir dos seres humanos, de modo que suas condutas passaram a ser realizadas de acordo com os meios eletrônicos informacionais, bem como as mídias de comunicação. Castells (1999, p. 108) afirma que uma das características deste novo padrão é a "penetrabilidade dos efeitos das novas tecnologias". Isso significa dizer que, sendo a informação necessária para as atividades dos seres humanos, todos os processos de sua existência passam a ser moldados pelos novos meios tecnológicos.

Neste contexto, Cremades (2009, p. 200) afirma que "a liberdade de expressão, com efeito, é parte essencial do micropoder surgido das mudanças sociais provocadas pela

\footnotetext{
${ }^{5}$ É livre a manifestação do pensamento, sendo vedado o anonimato.

${ }^{6}$ Artigo 220. A manifestação do pensamento, a criação, a expressão e a informação, sob qualquer forma, processo ou veículo não sofrerão qualquer restrição, observado o disposto nesta Constituição".
}

Rev. do Dir. do Trabalho e Meio Ambiente do Trabalho | e-ISSN: 2525-9857 | Salvador | v. 4 | n. 1 | p. 19 - 
interatividade proporcionada pelas tecnologias digitais". Essa nova percepção decorre do descomplicado acesso às redes proporcionam uma interação global entre as pessoas.

Portanto, sendo o mundo virtual uma reprodução do mundo real e a internet e redes sociais utilizadas como meios de propagação de informações e discursos de opiniões faz-se necessário estender a proteção dos direitos fundamentais e humanos ao ambiente virtual. Além disso, a massificação das novas tecnologias apresenta novas formas de bloqueios indevidos tanto quanto novas formas de aparentes conflitos de direitos fundamentais, especialmente ligadas ao direito da liberdade de expressão do pensamento, devendo ser garantidas "as oportunidades e capacidades comunicativas" de todos os membros da sociedade (MICHELMAN, apud SARLET, 2007, p. 51).

Destarte, a internet deixa de ser tão somente um meio de comunicação e passa a ser uma plataforma vista a partir de uma nova perspectiva, baseada na comunicação plural e interatividade entre os sujeitos. Em que pese possa-se observar uma maior uniformidade na distribuição das informações por meio das mídias sociais e demais formas de tecnologias, sendo possível que as informações cheguem aos indivíduos sem intervenção dos interlocutores, é possível, ainda, disseminar as opiniões e os discursos que violem direitos alheios (CREMADES, 2009, p. 204).

Portanto, não há dúvidas de que as tecnologias digitais, tanto quanto as medias sociais, foram revolucionárias em campos até então dominados, como o informacional e de comunicação, tornando os internautas interlocutores da notícia e construtores da informação. Consequentemente, valorizar os acessos às novas tecnologias e redes sociais é requisito para fomentar a participação dos cidadãos de todas as classes e, com isso, promover a democracia.

Isto porque as novas tecnologias possuem custo muito menor dos meios de comunicação tradicionais (televisão e rádio), ampliando a liberdade de expressão aos cidadãos de classe econômica desprivilegiada. Ora, com a viabilização da ampla comunicação igualitária, há ampliação da liberdade de expressão e, consequentemente, possibilita novos conflitos, vez que o alcance das publicações realizadas é mais extenso que aqueles já existentes.

Sendo as novas tecnologias e redes sociais propagadoras da liberdade de expressão e pensamento de seus internautas, faz-se necessário adequar as normas e formas de limitar esta liberdade a este novo modelo de propagar informações e opiniões, aplicando às normas jurídicas já existentes as novas formas de utilizá-los. É o que se compreende como novos direitos, devendo ser aplicados aos casos de uso (ir)responsável da liberdade de expressão e 
pensamento nas redes sociais da mesma forma que a palavra escrita e oral já prevista constitucionalmente.

Inobstante todas as garantias de liberdades, porquanto garantidoras da própria democracia que fundamenta o Estado Brasileiro, é preciso destacar que nem sempre há o respeito mútuo e a conciliação daqueles que usufruem de seus direitos, muitas vezes extrapolando as garantias positivadas e invadindo direitos alheios. Nesse contexto que se estuda as limitações previstas às liberdades de expressão e pensamento, principalmente a violação de direitos de outros indivíduos, mais corriqueiramente à ofensa à honra.

A liberdade de pensamento e de expressão, diz respeito à liberdade de manifestação de pensamento. O ser humano, em seu ímpeto, pode ter preconceitos e opiniões sobre as diversas situações que vivencia, mas a sua explanação não pode ser ofensiva a outro cidadão. O direito de expressão, no entanto, não é absoluto. Desta forma, a liberdade do indivíduo deve ser limitada em grande parte, sendo que não pode ser um incômodo para outrem.

A proibição ao anonimato é bastante ampla. Com o intuito de evitar manifestações que tenham como alvo apenas o desrespeito a outros direitos fundamentais, por motivos fúteis e torpes, o poder constituinte vedou as manifestações anônimas de todas as formas - carta, telefônica, internet. Neste norte, Novelino (2000. p. 297-298) discorre sobre a manifestação de pensamento, e por ter a possibilidade de ferir direitos fundamentais dos cidadãos deve sempre ser feita por autor identificado, tendo em vista que possível transgressão às garantias alheias possa ser devidamente punida, tanto na esfera cível quanto ao crime.

Embora defeso o anonimato e o uso da liberdade como forma de desrespeitar direitos de outrem, não há como se impedir que ofensas sejam feitas, portanto o que está ao alcance dos Poderes Públicos é a imposição de advertências a quem os comete. O direito de resposta, por exemplo, é a defesa de quem se sentiu prejudicado com a expressão do pensamento de outrem, uma reação ao uso indevido da mídia, configurando um meio de satisfação que é devido àquele que sofreu violação ao seu direito a imagem e a honra, que deve ser somado à pecúnia de danos morais que lhe serão devidos.

Outra forma de limitar a liberdade de expressão é a edição de leis para preservar os valores da juventude. Qualquer valor abrigado pela Constituição Federal do Brasil pode entrar em conflito com a liberdade. Entretanto, inobstante o jovem ter um direito não fundamental atingido, a Constituição Federal Brasileira dispõe de total prioridade quanto seus interesses, 
fundamentando que os meios pelos quais as crianças e adolescentes serão ilesos "de toda forma de discriminação, violência, exploração, crueldade e opressão"”.

Desta forma, a liberdade de expressão poderá ser reprimida no momento em que coloca em risco uma educação democrática, afastada de qualquer ira de preconceito e fundada nos princípios do ser humano, não colocando em risco o direito à liberdade. Por fim, deve-se destacar que a liberdade de expressão do pensamento é um direito característico dos regimes estatais democráticos e que está intimamente ligada ao direito a honra, a imagem, a informação, podendo ser restritos nas condições que fere a moral e os bons costumes, além dos demais direitos fundamentais sobre outro sujeito.

É nesse diapasão que o presente artigo será desenvolvido: estudar as liberdades especialmente a liberdade de expressão do pensamento - na legislação constitucional brasileira, para poder compreendê-las inseridas no ambiente de trabalho e estudar a validação de sua limitação por meio do poder diretivo, analisando-as por meio do balancing test (SCHWARZ, 2015, p. 44).

\section{A LIBERDADE DE MANIFESTAÇÃO DO PENSAMENTO DO TRABALHADOR EM REDES SOCIAIS E O PODER DIRETIVO DO EMPREGADOR}

A relação jurídica pressupõe a existência de duas pessoas e um vínculo jurídico entre elas. Em especial no caso do direito do Direito de Trabalho, o objetivo da elaboração de um contrato é diminuir a distância entre os direitos elencados na Consolidação das Leis Trabalhistas e àqueles efetivamente exercidos aos trabalhadores. A relação de emprego, com suas características próprias, não se enquadra em nenhum modelo de contrato existente em outras áreas, mas possui um contrato próprio, autônomo e com características particulares. A caracterização do contrato de trabalho ultrapassa o horizonte da conceituação, abrangendo elementos componentes essenciais do contrato e o nexo que os mantém interligados.

Dentre as características do contrato de trabalho já sedimentadas pelos estudiosos da área trabalhista, a subordinação é a propriedade que interessa a este estudo, vez que o poder diretivo decorre de sua relevância. Doutrinariamente, pode ser dividida em técnica, econômica e jurídica, sendo a última adotada para fins de composição contratual (ALELUIA,

\footnotetext{
${ }^{7}$ Art. 227. É dever da família, da sociedade e do Estado assegurar à criança, ao adolescente e ao jovem, com absoluta prioridade, o direito à vida, à saúde, à alimentação, à educação, ao lazer, à profissionalização, à cultura, à dignidade, ao respeito, à liberdade e à convivência familiar e comunitária, além de colocá-los a salvo de toda forma de negligência, discriminação, exploração, violência, crueldade e opressão.
}

Rev. do Dir. do Trabalho e Meio Ambiente do Trabalho | e-ISSN: 2525-9857 | Salvador | v. 4 | n. 1 | p. 19 - 
2015$, p. 75$)^{8}$. É valido ressaltar que a relação jurídica de trabalho decorre, de forma essencial, da causa inicial do acordo: o encontro das vontades do empregado e do empregador, formando poderes e deveres recíprocos, qual sejam de comando e obediência, prestação de serviço e de remuneração.

O artigo terceiro da Consolidação das Leis do Trabalho conceitua o empregado e, nesta descrição alude à dependência que, nos dias atuais é considerada apenas jurídica, resultante do ajuste dos contratos de trabalho. A relação de emprego reconhece, como elemento intrínseco do contrato de trabalho, a subordinação jurídica, uma vez que todo poder proveniente do empregador corresponde necessariamente a um dever a seu favor.

A subordinação jurídica possui classificação própria, podendo ser compreendida como clássica; objetiva; ou estrutural, dependendo do modo como a empresa se estrutura e lida com seus funcionários. A primeira consiste na submissão do trabalhador à vontade de outra por meio de uma submissão funcional, com o intuito de unificar a coordenação de atividades diversas, sendo desconexo de qualquer submissão psicológica ou obediência pessoal. De outro quadrante, a subordinação estrutural assegura que basta o trabalhador estar inserido na atividade fim da empresa para estar subordinado estruturalmente ao empresário, sendo que o vínculo é extraído pela inserção do empregado no processo produtivo (estrutura) da empresa.

A subordinação objetiva é aquela que recai sobre "o serviço prestado, como decorrência direta do contrato de trabalho" (ALELUIA, 2015, p. 77), logo, quem está subordinado é o próprio serviço, não o empregado. Tal visão amplia os horizontes do conceito de empregado, englobando os trabalhadores externos, em domicilio ou teletrabalho. Nestes casos específicos a fiscalização recai sobre o serviço por ele prestado, restando comprovada a subordinação pela obrigatoriedade no cumprimento das metas.

Entretanto, por mais beneficente que seja ao trabalhador, há uma crise sobre a subordinação objetiva, que consiste na faculdade do empregador em impor sanções disciplinares ao trabalhador, bem como a incorporação não apenas o trabalho de seus

\footnotetext{
${ }^{8}$ A subordinação técnica é aquela em que o empregador precisaria apresentar superioridade em relação ao empregado sendo necessário que entendesse mais do serviço prestado do que o empregado. A subordinação econômica também não é a adotada pela legislação brasileira vez que independente do poder econômico do empregado, ele sempre deverá obedecer às ordens de seu superior. Portanto, a subordinação que envolve as partes do acordo de trabalho é unicamente jurídica, decorrente de contrato, sendo um dever do empregado pelo fato de ter firmado um contrato com seu empregador, ajustando que o empregado estará sujeito às ordens do empregador (no limite da não abusividade ou ilegalidade).
} 
empregados, mas a atividade de colaboradores - não empregados - incorporados ao desenvolvimento econômico da empresa.

A subordinação objetiva é, por sua vez, aquela que subordina o trabalho, independente onde ele seja realizado, fazendo, assim, com os colaboradores que trabalham em casa também sejam beneficiados com esta característica do contrato de trabalho, caso ele contribua para o desenvolvimento da atividade fim da empresa. Desta Forma, a subordinação é "o contraponto do contrato de trabalho que implica, para o empregado, abrir mão de parcela da sua liberdade, a fim de que atenda às ordens emanadas do seu empregador" (ALELUIA, 2015, p. 75).

Decorrente da subordinação do empregado surge o poder diretivo do empregador, cuja essência deriva da premissa de que o poder subsiste desde que haja uma capacidade de impor a vontade de alguém em alguma relação social. De forma proeminente, Maquiavel (2000, p. 96) entende que o homem é completamente vulnerável e demonstrará total lealdade a quem lhe presta ordens enquanto todas suas necessidades forem supridas, enquanto diante à dificuldade, há revolta. É o que se denota das relações de trabalho modernas, vez que o trabalhador dispõe de parte de sua liberdade e seu trabalho para obedecer às ordens de seu empregador para adequar-se às finalidades da empresa para qual foi contratado.

Sob a ótica do direito trabalhista, o poder encontra respaldo na subordinação do empregado, permitindo que o empregador possua alguns poderes específicos para nortear os serviços do trabalhador e organizar as atividades da empresa. Didaticamente, o poder diretivo também possui desmembramentos com o intuito de entendê-lo e descobrir seus limites em poder de direção, de organização, de controle e disciplinar.

O poder de direção é aquele que organiza a prestação de serviços e a produção dos bens fornecidos pela empresa. Dele decorrem os outros três poderes inerentes à profissão: o poder organizacional, de controle e disciplinar. Deverá o empregador orientar e fiscalizar todos os trabalhadores, punindo as irregularidades cometidas no decorrer das atividades e mantendo a ordem e disciplina da empresa.

O poder de organização, por sua vez é o direito que o empregador tem de organizar seu empreendimento decorrente do direito fundamental de propriedade. Este poder concede o direito ao patrão de organizar seu grupo de atividades laborais, visando, evidentemente, o lucro da empresa. Não se compreende tal organização tão somente de forma econômica, mas cabe, também, ao empregador, formular a ordem social que decorre das atividades do empreendimento. 
O poder de controle refere-se a um dever de fiscalização das atividades profissionais de seus colaboradores, concedendo ao empregador o direito de controlar a execução dos serviços de seus empregados, bem como a maneira como estes foram prestados, além do comportamento do trabalhador. Este específico poder diretivo que, quando utilizado de forma excessiva, pode apresentar aparente choque com direitos fundamentais dos trabalhadores, a exemplo da liberdade de pensamento e expressão deste.

Isto é comum quando a forma de controle utilizada é por meio de tecnologias, como câmeras ou monitoramento de mensagens eletrônicas, além da possibilidade de limitação das redes sociais dos trabalhadores, que cada vez mais têm se mostrado propulsora das opiniões e propagação de informações. O estudo em tela salienta que, por vezes, o poder de controle ultrapassa a relação de trabalho e acaba ocorrendo violações entre direitos fundamentais decorrente das expressões de pensamentos nas redes sociais que desrespeitem as visões e princípios a empresa empregadora.

Por fim, o direito disciplinar corresponde à aplicação do poder no que tange as punições caso alguma ordem sua seja descumprida. Por certo que deve ser usado de forma equilibrada e usado proporcionalmente à gravidade do ato cometido pelo empregado. Os modos de sansão que podem ser aplicados aos trabalhadores são advertência verbal, advertência escrita e suspensão, para faltas disciplinares ou insubordinação leve, média e mais grave respectivamente. Este poder é "relacionado com o poder diretivo, sendo-lhe atribuída a função que garante a eficácia deste poder, sem a possibilidade de reagir contra o trabalhador pelo não cumprimento das emanações do poder de direção" (RAMALHO, 1993, p. 185).

A organização demostrada e a necessidade de concessão de poderes ao empregador para gerir o empreendimento cuja atividade econômica é a razão pela qual os trabalhadores podem desenvolver suas profissões justifica-se nas responsabilidades do empregador lhe trazem tamanhos poderes, dizendo que "em qualquer regime econômico, é fundamental que as unidades produtoras, seja qual for seu porte, se organizem hierarquicamente, com vistas à realização de seus objetivos" (PEREIRA, 1991, p. 9). Ou seja, a medida do sacrifício feito pelo empregado ao entregar parcela de sua liberdade ou autonomia em mãos do empregador durante a prestação de serviço deve ser colocada da mesma forma a dependência jurídica de seu respectivo empregador.

A liberdade de pensamento e expressão deve ser entendida, como bem descrito no primeiro capitulo deste trabalho, como prioritária, contudo não ilimitada. Nesta toada, a liberdade pode sofrer restrições na relação de trabalho, quando preenchidos três requisitos: “a 
necessidade da regra imposta, a adequação desta regra e a proporção em que ela é imposta" $(\mathrm{TST}, 2012)^{9}$.

Neste contexto, Dray (2006. p. 72) defende a liberdade de manifestar os pensamentos dos trabalhadores no âmbito da empresa, apartando a subordinação ao empregador pela obediência de ordens referente ao serviço prestado e os direitos de personalidades do trabalhador. A exemplo, o TST negou provimento ao Agravo de Instrumento AIRR-23-0066.2008.5.02.0391 ${ }^{10}$ da empresa, afirmando o direito a liberdade do empregado, onde suas decisões de vida particular não devem ser correlatas com sua vida profissional. Neste caso, a empregada foi demitida por justa causa devido não retirar um piercing no nariz, após três suspensões por não tirar o adorno.

Pertinente ao referido assunto, e com convicção de que, em regra, os atos da vida privada não devem repercutir na vida pública, mas aceitando que, como toda regra, há exceções, vez que atitudes da vida privada que ganham publicidade e passam a interferir no seu trabalho são incompatíveis e, dentro do ambiente de trabalho, a subordinação presente na prestação de serviço é um fator lícito de limitação da liberdade.

Destarte, um direito deve ser limitado quando confrontado com outro para determinar seu alcance material, portanto, o limite de um direito fundamental é seu alcance material, e só pode ser determinado por meio da interpretação (ROMITA, 2015, p. 1070). Ocorre que, esta celeuma causa um abalo na segurança jurídica dos indivíduos, ao passo que há um "espaço de incerteza" entre o que o texto do legislador e sua efetiva aplicação.

A aparente colisão entre os direitos ocorre quando dois titulares de direitos fundamentais reclamam para si o uso de liberdades que se excluem reciprocamente. Portanto, “dois direitos colidem quando o exercício de um deles por parte de seu titular prejudica o uso de direito fundamental por parte do outro titular, como ocorre, por exemplo, entre a liberdade de expressão" (ROMITA, 2015, p. 1071).

Reconhece-se, contudo, que tanto o poder diretivo do empregador - decorrente da livre iniciativa - quanto o direito a liberdade do empregado são direitos constitucionais e devem coexistir, não podendo negar a vigência da Constituição Federal para dizer qual direito possui maior relevância. Certifica-se, inclusive, que é extremamente complexa a resoluções de casos concretos em que ambos estes direitos fundamentais encontram-se violados. É neste viés que se estuda o "balancing test" como técnica judicial de ponderação entre o poder

\footnotetext{
${ }^{9}$ http://www.tst.jus.br/materias-especiais/-/asset_publisher/89Dk/content/id/3253359

${ }^{10}$ TST, Relator: Luiz Philippe Vieira de Mello Filho, Agravo de Instrumento AIRR-23-00-66.2008.5.02.0391. Data de Julgamento: 09/11/2011, $1^{a}$ Turma).
} 
diretivo do empregador e o direito fundamental entre a liberdade de manifestação do pensamento do trabalhador.

\section{O "BALANCING TEST" COMO TÉCNICA JUDICIAL DE PONDERAÇÃO, ENTRE O PODER DIRETIVO DO EMPREGADOR E O DIREITO FUNDAMENTAL DE LIBERDADE DE MANIFESTAÇÃO DO PENSAMENTO DO TRABALHADOR}

Por não serem absolutos, nem ilimitados, tanto o poder diretivo do empregador quanto o direito fundamental entre a liberdade de manifestação do pensamento do trabalhador apresentam um caráter aberto, exigindo da interpretação a tarefa de harmonizar estes direitos. Inobstante as evidências acerca das aparentes colisões de direitos fundamentais, o ordenamento jurídico brasileiro é falho no que tange às diretrizes aos magistrados para tomar decisões deste crivo, avalizando decisões bem argumentadas quando decorrem tão somente da transcrição moral do magistrado, sem corresponder a qualquer critério científico.

As liberdades, em especial, apresentam-se nos mais diversos conflitos de direitos, e incidem diretamente nas relações de trabalho subordinado, sendo possível que os dissídios decorrentes de tais conflitos podem ser solucionados a partir do manejo dos princípios pertinentes ao caso concreto.

Para tanto, é preciso levar em consideração que a liberdade de manifestação de pensamento é imprescindível para formação de uma opinião politica e cultural, contudo, o empregador, ao limitar a liberdade de seus empregados, pauta-se em seus direitos constitucionais do valor social do trabalho ${ }^{11} \mathrm{e}$ da valorização da livre iniciativa ${ }^{12}$.

Neste norte, quando se deparam com questões delicadas como esta apontada acima, os julgadores precisam critérios de análise para não julgarem de acordo com suas consciências e, a partir de uma fundamentação robusta, decidir pelos seus princípios ético, garantindo maior neutralidade com os fatos do caso concreto. Importante destacar que a ponderação deve ser feita em momentos diversos: o primeiro consiste na máxima conservação dos interesses em questão e o segundo em qual dos princípios irá prevalecer, por melhor atender a vontade constitucional.

\footnotetext{
${ }^{11}$ Art. $1^{\text {o }}$ A República Federativa do Brasil, formada pela união indissolúvel dos Estados e Municípios e do Distrito Federal, constitui-se em Estado Democrático de Direito e tem como fundamentos: IV - os valores sociais do trabalho e da livre iniciativa;

12 Art. 170. A ordem econômica, fundada na valorização do trabalho humano e na livre iniciativa, tem por fim assegurar a todos existência digna, conforme os ditames da justiça social, observados os seguintes princípios.
}

Rev. do Dir. do Trabalho e Meio Ambiente do Trabalho | e-ISSN: 2525-9857 | Salvador | v. 4 | n. 1 | p. 19 39 | Jan/Jun. 2018 
De um modo geral, enquanto em abstrato os princípios possuem todos a mesma força normativa, quando surge a situação em concreto, e a aparente colisão entre os mesmos - em especial entre o direito de liberdade de pensamento e expressão e o direito da iniciativa privada do empregador - é preciso que se pondere para perceber qual princípio triunfará.

O Tribunal Superior do Trabalho também apresenta situações em que os motivos alegados para demissão se deu devido o uso indevido de equipamentos de trabalho para atender a esfera pessoal. Isto reflete diretamente na liberdade de expressão do empregado no ambiente de trabalho.

Exemplo disso ocorreu no município Cândido de Abreu/Paraná (TST, 2010), em que uma servidora pública que estava no cargo há mais de dez anos teve sua gratificação suprimida por discordar das convicções políticas do prefeito local. Quando o caso alcançou no TST, a Relatora Rosa Webber entendeu, de forma certeira, que tal limitação à liberdade de expressão era ilegal e feria o direito fundamental da empregada.

Em contrapartida, na cidade paulista de Itu, o servidor público da prefeitura publicou em rede social palavras ofensivas em relação ao prefeito, alertando aos cidadãos, inclusive, que não deveriam mais "votar em certos pilantras que nomeiam incompetentes para administrarem os setores da municipalidade" (TRT 15, 2010).

Audaciosamente, este empregado sentiu-se ofendido quando da visita do prefeito e de um dos secretários em sua sala para receber explicações, bem como alegou que publicou as mensagens em fulcro na liberdade de expressão. De forma ainda mais ousada, em 2007 ingressou com ação trabalhista contra o município, causa esta que restou julgada procedente, em que os juízes argumentam que os comentários "eram de conhecimento público e notório de qualquer cidadão". Não é o que se entende por justiça.

Parte da doutrina manifestou-se no sentido de que "as convicções do empregado, pelo menos no que tange ao exercício das tarefas indispensáveis à atividade empresarial, devem coadunar-se com a ideologia e as crenças perfilhadas pelo empregador”. Desta forma, enquanto o ordenamento jurídico brasileiro não aperfeiçoar a maneira como deverá ser analisados os casos concretos, continuará sendo responsabilidade dos magistrados resolver os casos concretos que os códigos não norteiam (ROMITA, 2015, p. 1071).

Assim, a liberdade como direito social vislumbrada no âmbito trabalhista, especificamente à possibilidade de sua limitação, por ser direito fundamental de primeira geração aplicada a direitos prestacionais de proteção ao hipossuficiente - os trabalhadores deve ser aplicada por meio dos elementos básicos que integram a "prova" de 
proporcionalidade em alguns ordenamentos contemporâneos, como o alemão, ao qual podemos recorrer por meio do direito comparado.

Essa forma de ponderação, influenciada pela doutrina norte-americana, aplicáveis em casos em que a subsunção se mostrou insuficiente, especialmente quando a situação em concreto possui aplicação de normas de mesma hierarquia que indicam soluções diferentes. Portanto, o "balancing test" é uma "técnica jurídica de solução de conflitos normativos que envolvem valores ou opções políticas em tensão, insuperáveis pelas formas hermenêuticas tradicionais" (BARCELLOS, 2005, p. 23).

Neste diapasão, nos casos concretos que admitirem aplicação e vários princípios e mesmo nível hierárquico, é necessária a conexão e análise dos mesmos para que possa ser realizada a ponderação, cujo resultado apresentará a regra a ser aplicada no caso. A decisão tomada, portanto, obedecerá á ambos os princípios em discussão, jamais anulando qualquer um deles (BARROSO, 2004, p. 357).

Portanto, inobstante a estrutura da ponderação ainda não seja conhecida em sua plenitude, é possível vislumbrar uma evolução para ponderações intensamente estruturadas, sejam quais forem seus elementos, que poderá ser utilizada na aplicação dos postulados específicos. Para tanto, selecionam-se critérios específicos a fim de realizar o teste de balanceamento nos exemplos acima trazidos e verificar se é válida a limitação imposta ao direito fundamental de expressão do pensamento no caso concreto.

Esses critérios incluiriam: a) a legitimidade da matéria em pauta, ou seja, sua vinculação ao ordenamento e, sobretudo, aos fins prescritos; b) a adequação da medida em pauta, ou seja, seu caráter realmente adequado à proteção dos fins prescritos; c) a necessidade da medida em pauta, ou seja, seu caráter imprescindível e, antes de mais nada, a inexistência de meios menos onerosos para os resultados afetados; e d) a proporcionalidade, em sentido estrito, da medida em pauta, ou seja, se dela derivam mais benefícios ou vantagens de interesse geral do que para outros bens e valores em conflito ${ }^{13}$.

No primeiro caso (do Paraná) encontram-se cristalinos o direito à liberdade de expressão da servidora e o poder diretivo do prefeito local, sendo, portanto, legítima a matéria em pauta, bem como sua adequação, por se tratar de matérias previstas como direitos fundamentais. A necessidade de medida em pauta se demonstra pela redução da gratificação da servidora, cujos rendimentos foram suprimidos por conta da manifestação de um

\footnotetext{
${ }^{13}$ Para mais formulações nesse sentido, v. Pulido (2003).
} 
pensamento político, sendo possíveis outras medidas para reprimir a funcionária que, inclusive, não causou grandes prejuízos ao prefeito.

Quanto à proporcionalidade, tendo em vista que não houve prejuízos de ordem material ao prefeito, sendo somente uma divergência entre opiniões políticas difundidas por funcionária pública contratada por meio de concurso público, e tendo em vista que a atitude poderia ter sido revista a partir de advertência verbal ou mesmo solicitação de não exposição sem interferir na contraprestação de seu trabalho - que continuava sendo realizado como esperado - não houve proporcionalidade na atitude tomada, motivo pelo qual a decisão da Ministra Relatora Rosa Webber em declarar a ilegalidade da limitação é a medida adequada por meio da aplicação dos critérios do balancing test.

$\mathrm{O}$ segundo caso apresentado (Cidade de Itu/SP) depreende-se o direito à honra do prefeito sendo violada por meio do direito à liberdade de expressão do pensamento do servidor público, sendo legítimos os direitos em aparente conflito. Haja vista que o servidor público maculou a honra do prefeito local em rede social, cuja propagação se dá de forma desenfreada, realizando sérias acusações contra seu superior sem qualquer prova, torna-se imprescindível que seja tomada alguma medida a fim de cessar a violação ao direito da honra do administrador municipal.

Além disso, a partir da afirmação de que o trabalhador recebeu visita do prefeito e de um dos secretários em sua sala para receber explicações acerca do assunto antes de qualquer medida punitiva, se mostra proporcional a limitação da liberdade de expressão do sujeito, sendo que as acusações não eram apenas ofensivas à honra do prefeito, mas aos servidores contratados para trabalhar na administração do mesmo, motivo pelo qual a decisão de que os comentários já eram de conhecimento dos cidadãos não se mostra adequada ao caso se analisado pelo método do "balancing test".

Diante da não preponderância de um direito fundamental sobre outro, quando do conflito entre eles, um dos direitos - no caso estudado o direito a liberdade de expressão do empregado ou a iniciativa privada do empregador - um deles deverá ceder perante o outro, o que não significa que será invalidado.

Para que seja eficaz e a mais correta possível a decisão do magistrado, é preciso que este atenda a três critérios da ponderação, quais sejam: “a cuidadosa análise das características do caso em exame [...] determinar qual dos dois direitos é mais digno de proteção [...] lembrar que a técnica da ponderação não dá respostas em termos de sim ou não, porém de mais ou menos" (ROMITA, 2015, p. 1071). 
Desta forma, se obedecidos os requisitos da ponderação, poderá ser encontrado um ponto de equilíbrio entre os valores em questão com maior cientificidade, para que aquele que não prevaleça possa ser classificado única e exclusivamente na medida necessária, garantindo seu núcleo absoluto, defendido pela razoabilidade.

Conclui-se, assim, a partir dos estudos doutrinários e da pesquisa jurisprudencial que não há uma resposta em abstrato para os casos em que apresentam aparentes conflitos entre a liberdade de expressão no ambiente de trabalho e sua possibilidade de limitação pelo empregador, devendo ser analisadas caso a caso, com critérios objetivos para então, ponderadamente, definir se, em casos de limitação da liberdade de expressão do trabalhador, a medida é possível ou uma violação ao seu direito fundamental.

\section{CONCLUSÃO}

A partir da análise das concepções de liberdade de expressão do pensamento no direito brasileiro, tanto em sua forma tradicional quanto nas redes sociais decorrentes de novas tecnologias de informações, e sua limitação decorrente da relação de trabalho, por meio de uma pesquisa bibliográfica cujo método utilizado foi o dedutivo, denota-se que nem sempre os tribunais utilizam-se dos critérios da técnica judicial de ponderação do "balancing test" para apreciar os casos de aparente conflito de direitos fundamentais, o que torna a discricionariedade a verdadeira técnica de suas decisões.

Decorrente dos possíveis conflitos resultantes das pretensões que aparentemente colidem estas liberdades (em especial à liberdade de expressão do pensamento) o Estado se justifica, incumbido de garantir a paz de seus cidadãos. Neste diapasão, em que pese o direito brasileiro preveja possibilidades de limitação deste direito, principalmente quando há violação de outros, é necessária a intervenção do poder judicial para validar a extensão destes limites.

Isto porque, em que pese à liberdade de manifestação e pensamento seja um direito característico dos regimes estatais democráticos, garantidor da própria democracia, está intimamente ligada ao direito à honra, imagem, e informação, podendo ser restritos nas condições que fere a moral e os bons costumes, além dos demais direitos fundamentais sobre outro sujeito, como forma de garantir a ordem social.

Esta possibilidade de limitação das expressões de pensamento de forma livre, inclusive nas mídias sociais, acaba se tornando extremamente frágil, vez que autoriza o empregador a tomar medidas invasivas aos trabalhadores, limitando suas liberdades de forma 
desmedida sob o argumento de que tal direito não é absoluto e está em desacordo com as premissas da empresa em que laboram.

Portanto, compreende-se que as liberdades conquistadas não possuem condão absoluto, muito embora sejam, por diversas vezes, protagonistas dos direitos que dela derivam, podendo ser restringidas quando desrespeita outras garantias fundamentais, sem que isso se caracterize como violação da própria liberdade.

Diante desta contingência, estudam-se dois casos em que a liberdade de expressão de pensamento do trabalhador foi utilizada em mídias sociais e limitada em decorrência da relação de trabalho entre as partes. Em uma delas parece estar em acordo com os parâmetros estabelecidos pela técnica de ponderação do "balancing test" e proporcional aos propósitos que foram previstas as limitações das liberdades.

De outro quadrante, o segundo caso apresenta uma decisão judicial desmedida, que é julgada por meio da discricionariedade dos magistrados e avalizada por uma boa argumentação fundamentada na ponderação sem qualquer critério de análise. Esse é um exemplo de decisões que não se preocupa com critérios materiais para análise dos casos concretos e acaba sendo o reflexo das próprias convicções dos magistrados, o que muito preocupa a academia.

Portanto, os limites razoáveis para a validade jurídica de uma limitação imposta à liberdade de expressão do pensamento realizada por meio do poder diretivo decorrente da relação de trabalho entre as partes podem sim ser verificados a partir da técnica judicial do "balancing test", em um caso concreto, isso quando e tão somente, quando os critérios de legitimidade; adequação; necessidade; e proporcionalidade forem cumpridos de forma material.

\section{REFERÊNCIAS BIBLIOGRÁFICAS}

ALELUIA, Thais Mendonça. Direito do Trabalho. Bahia: Editora JusPodivm, 2015.

BARCELlOS, Ana Paula de. Ponderação, Racionalidade e Atividade Jurisdicional. Rio de Janeiro: Renovar, 2005.

BARROSO, Luís Roberto. Interpretação e Aplicação da Constituição. $6^{\circ}$. ed. rev., atual. e ampl.-São Paulo: Saraiva, 2004.

CASTELLS, Manuel. A sociedade em rede. 6. ed. São Paulo: Paz e Terra, 1999. 
CREMADES, Javier. Micropoder: a força do cidadão na era digital. Tradução de Edgard

Charles. São Paulo: Editora Senac São Paulo, 2009.

DRAY. Guilherme Machado. Direitos da personalidade: Anotações ao Código Civil e ao

Código do Trabalho. Rio de Janeiro: Almedina. 2006.

HOBBES, Thomas. Leviatã. Coleção a obra-prima de cada autor. São Paulo: Editora Martin Claret, 2009.

MACHIAVELLI, Niccolo. O Príncipe. Rio de Janeiro: Bertrand Brasil. 2000.

MARX, Karl. Manuscritos econômicos. São Paulo: Boitempo, 2004.

MICHELMAN, Frank. Relações entre democracia e liberdade de expressão: discussão de alguns argumentos. In SARLET, Ingo. Wolfgang (org). Direitos Fundamentais, Informática e Comunicação: algumas aproximações. Porto Alegre: Livraria do Advogado, 2007.

MILL, John Stuart. Ensaio sobre a liberdade. São Paulo: Editora Escala, 1086.

MONTESQUIEU, apud CHEVALIER, Jean Jacques. As grandes obras políticas de Maquiavel a nossos dias. Trad. Lydia Cristina. 8. ed. Rio de Janeiro: Agir, 1998.

MORAES, Alexandre Fernandes de. Direitos Humanos Fundamentais. 4. ed. São Paulo: Editora Atlas, 2002.

NOVELINO, Marcelo. Direito Constitucional. 2. ed. São Paulo: Editora Método, 2000.

ORGANIZAÇÃO DAS NAÇÕES UNIDAS. Declaração Universal dos direitos Humanos.

1948. ONU. Disponível em: <http://www.ohchr.org/EN/UDHR/Documents/

UDHR_Translations/por.pdf >. Acesso em: 18 nov. 2017.

PEREIRA, Adilson Bassalho. A Subordinação como objeto do contrato de emprego. São Paulo: LTr, 1991.

RAMALHO, Maria do Rosário Palma. Do fundamento do poder disciplinar laboral. Coimbra: Editora Almedina. 1993.

ROMITA, Arion Sayão. Colisão entre direitos: liberdade de expressão e ofensa à honra e à imagem. LTR Legislação do Trabalho. São Paulo, v. 79, n. 09, 2015.

SCHWARZ, Rodrigo. As garantias dos direitos fundamentais sociais: uma perspectiva garantista e democrática. Joaçaba: Unoesc, 2015.

TRT 15. Tribunal Regional do Trabalho 15, RO 0153900-63.2007.5.15.0018, Relatora: Thelma Helena Monteiro de Toledo Vieira. DJ: 12/03/2010., 2010.

TST. Tribunal Superior do Trabalho: TST-RR-32000-81.2005.5.09.0073. Relatora: Ministra Rosa Webber. DJ:18/08/2010, 2010. 